\title{
Letter
}

\section{4,5-Diazafluorene-Incorporated Ter(9,9-diarylfluorene): A Novel Molecular Doping Strategy for Improving the Electron Injection Property of a Highly Efficient OLED Blue Emitter}

Ken-Tsung Wong, Ruei-Tang Chen, Fu-Chuan Fang, Chung-chih Wu, and Yu-Ting Lin

Org. Lett., 2005, 7 (10), 1979-1982• DOI: 10.1021/ol050547o • Publication Date (Web): 12 April 2005

Downloaded from http://pubs.acs.org on February 17, 2009

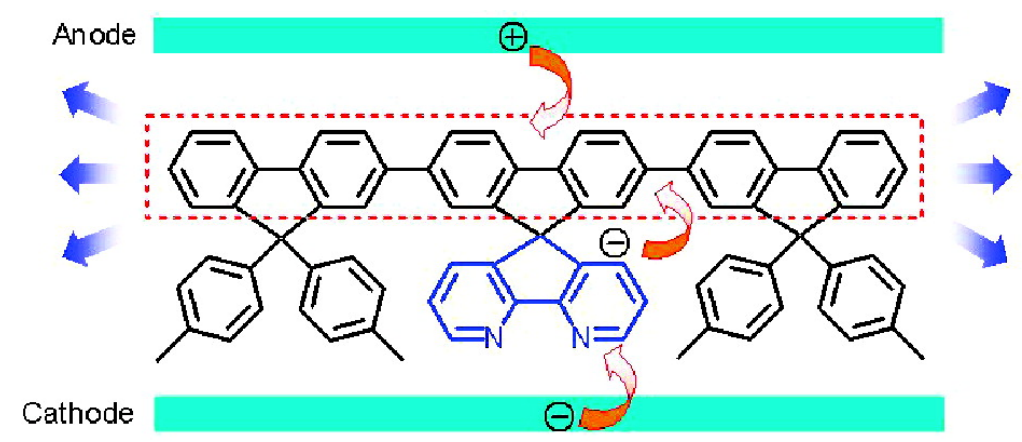

\section{More About This Article}

Additional resources and features associated with this article are available within the HTML version:

- $\quad$ Supporting Information

- $\quad$ Links to the 9 articles that cite this article, as of the time of this article download

- $\quad$ Access to high resolution figures

- $\quad$ Links to articles and content related to this article

- $\quad$ Copyright permission to reproduce figures and/or text from this article

\section{View the Full Text HTML}




\author{
Ken-Tsung Wong, ${ }^{*, \dagger}$ Ruei-Tang Chen, ${ }^{\dagger}$ Fu-Chuan Fang, ${ }^{\dagger}$ Chung-chih Wu, ${ }^{*, \neq}$ and \\ Yu-Ting Lin $¥$ \\ Department of Chemistry, National Taiwan University, Taipei 106, Taiwan, and \\ Department of Electrical Engineering, Graduate Institute of Electro-optical \\ Engineering and Graduate Institute of Electronics Engineering, National Taiwan \\ University, Taipei 106, Taiwan
}

kenwong@ntu.edu.tw

Received March 14, 2005

\title{
ABSTRACT
}

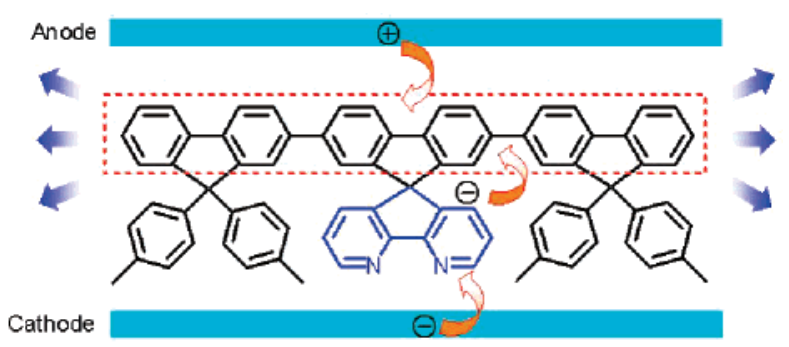

A more efficient OLED device with blue emission characteristic of terfluorene has been achieved by using a novel molecular doping strategy, in which 4,5-diazafluorene was incorporated as the substitution group of terfluorene to facilitate electron injection from the metal cathode yet without altering emission characteristics.

Oligomeric fluorenes with high thermal stability, high solution- and solid-state fluorescence quantum yields, ${ }^{1}$ and high bipolar charge carrier mobilities ${ }^{2}$ are promising for highly efficient blue OLEDs. However, due to large carrier-

\footnotetext{
$\doteqdot$ Department of Chemistry, National Taiwan University.

Graduate Institute of Electro-optical Engineering and Graduate Institute of Electronics Engineering, National Taiwan University.

(1) (a) Spehr, T.; Pudzich, R.; Fuhrmann, T.; Salbeck, J. Org. Elec. 2003, 4, 61. (b) Geng, Y.; Katsis, D.; Culligan, S. W.; Ou, J. J.; Chen, S. H.; Rothberg, L. J. Chem. Mater. 2002, 14, 463. (c) Wong, K.-T.; Chien, Y.Y.; Chen, R.-T.; Wang, C.-F.; Lin, Y.-T.; Chiang, H.-H.; Hsieh, P.-Y.; Wu, C.-C.; Chou, C. H.; Su, Y. O.; Lee, G.-H.; Peng, S.-M. J. Am. Chem. Soc. 2002, 124, 11576.

(2) (a) Wu, C.-C.; Liu, T.-L.; Hung, W.-Y.; Lin, Y.-T.; Wong, K.-T.; Chen, R.-T.; Chen, Y.-M. Chien, Y.-Y. J. Am. Chem. Soc. 2003, 125, 3710 (b) Wu, C.-C.; Liu, T.-L.; Lin, Y.-T.; Hung, W.-Y.; Ke, T.-H.; Wong, K.T.; Chao, T.-C. Appl. Phys. Lett. 2004, 85, 1172.
}

injection barriers between oligofluorene derivatives and corresponding electrodes, efficient emitting devices using fluorenes as emitters normally still require sophisticated configurations incorporating both suitable hole-transporting and electron-transporting layers. For improving the carrier injection capability, structural modifications of the conjugated fluorene backbone can be adopted by introducing heteroaromatic rings as functional components. However, molecular design based on such a strategy would greatly perturb structural features of the main chain and thus physical properties of materials. ${ }^{3}$ By making use of flexibility in functionalizing C-9 positions of fluorenes, such complexity may be reduced through development of multifunctional fluorene-based materials containing pendant groups of dif- 
ferent functionalities. ${ }^{4}$ With such a configuration, the tetrahedral C-9 carbon of fluorene serves as an insulating spacer, ${ }^{5}$ effectively hindering interactions between the central fluorene chromophore and the C-9 substitution. In addition, materials covalently combining different functional subunits also avoid the problems of phase separation occasionally encountered in using the doping or blending strategy.

Among the oligofluorenes, ter(9,9-ditolylfluorene) (1) is one of the most efficient emitters for blue OLEDs. ${ }^{6}$ Yet for OLED applications, the electron affinity (Ea) of $\mathbf{1}$ is relatively small, causing difficulty in electron injection from common cathode electrodes and imposing the requirement of an additional electron-transport layer with a more suitable electron-injection capability. In this communication, 4,5diazafluorene ${ }^{7}$ has been facilely introduced as a functional substituent spirally linked to the conjugated terfluorene main chain. The resulting functionalized terfluorene (2) performs a more balanced electron injection capability as compared to the parent compound (1). The molecular design reported in this communication possesses the advantage of permitting the introduction of a higher electron affinity moiety without altering the emission properties of the oligomeric fluorene backbone.

The synthesis of the titled compound is depicted in Scheme 1. Starting from 4,5-diazafluoren-9-one, ${ }^{8}$ 4,5-diaza-9,9' spirobifluorene ${ }^{9}$ was synthesized in moderate yield $(70 \%)$ with modified procedures (Supporting Information). The selective bromination on the biphenyl branch of 4,5-diaza9,9'-spirobifluorene has been accomplished to afford 4,5diaza- $2^{\prime}, 7^{\prime}$-dibromo-9, $9^{\prime}$-spirobifluorene with a $66 \%$ isolated yield in the presence of $\mathrm{FeCl}_{3}$ as a Lewis acid promoter in $\mathrm{CH}_{2} \mathrm{Cl}_{2}$. The titled compound then was efficiently synthesized with an isolated yield of $86 \%$ by Suzuki coupling reaction

(3) (a) Kulkarni, A. P.; Zhu, Y.; Jenekhe, S. A. Macromolecules 2005, 38, 1553. (b) Kulkarni, A. P.; Kong, X.; Jenekhe, S. A. J. Phys. Chem. B 2004, 108, 8689. (c) Kong, X.; Kulkarni, A. P.; Jenekhe, S. A. Polym. Prepr. 2003, 44, 356. (d) Asawapirom, U.; Guntner, R.; Forster, M.; Farrell, T.; Scherf, U. Synthesis 2002, 9, 1136. (e) Belfield, K. D.; Morales, A. R.; Kang, B.-S.; Hales, J. M.; Hagan, D. J.; Van Stryland, E. W.; Chapela, V. M.; Percino, J. Chem. Mater. 2004, 16, 4634. (f) Yang, R.; Tian, R.; Yan, J.; Zhang, Y.; Yang, J.; Hou, Q.; Yang, W.; Zhang, C.; Cao, Y. Macromolecules 2005, 38, 244. (g) Liu, B.; Yu, W.-L.; Pei, J.; Liu, S.-Y.; Lai, Y.-H.; Huang, W. Macromolecules 2001, 34, 7932.

(4) (a) Ego, C.; Grimsdale, A. C.; Uckert, F.; Yu, G.; Srdanov, G.; Müllen, K. Adv. Mater. 2002, 11, 809. (b) Wu, F.-I.; Reddy, D. S.; Shu, C.-F.; Liu, M. S.; Jen, A. K.-Y. Chem. Mater. 2003, 15, 269. (c) Shu, C.F.; Dodda, R.; Wu, F.-I.; Liu, M. S.; Jen, A. K.-Y. Macromolecules 2003 36, 6698. (d) Kim, J. H.; Liu, M. S.; Jen, A. J. K.-Y.; Carlson, B.; Dalton, L. R.; Shu, C.-F.; Dodda, R. Appl. Phys. Lett. 2003, 83, 776. (e) Kim, J. H.; Herguth, P.; Kang, M.-S.; Jen, A. J. K.-Y.; Tseng, Y.-H.; Shu, C.-F. Appl. Phys. Lett. 2004, 85, 1116. (f) Niu, Y.-H.; Chen, B.; Liu, S.; Yip, H.; Bardecker, J.; Jen, A. K.-Y.; Kavitha, J.; Chi, Y.; Shu, C.-F.; Tseng, Y.H.; Chien, C.-H. Appl. Phys. Lett. 2004, 85, 1619. (g) Chen, X.; Liao, J.L.; Liang, Y.; Ahmed, M. O.; Tseng, H. E.; Chen, S.-A. J. Am. Chem. Soc. 2003, 125,636 .

(5) (a) Wu, F.-I.; Shu, C.-F.; Chien, C.-H.; Tao, Y.-T. Synth. Met. 2005 148, 133. (b) Nomura, M.; Shibasaki, Y.; Ueda, M.; Tugita, K.; Ichikawa, M.; Taniguchi, Y. Synth. Met. 2005, 148, 155.

(6) Wu, C.-C.; Lin, Y.-T.; Wong, K.-T.; Chen, R.-T.; Chien, Y.-Y. Adv. Mater. 2004, 16, 61.

(7) Ono, K.; Yanase, T.; Ohkita, M.; Saito, K.; Matsushita, Y.; Naka, S.; Okada, H.; Onnagawa, H. Chem. Lett. 2004, 33, 276.

(8) (a) Mazaleyrat, J.-P.; Wright, K.; Wakselman, M.; Formaggio, F.; Crisma, M.; Toniolo, C. Eur. J. Org. Chem. 2001, 10, 1821. (b) Baxter, P. N. W.; Connor, J. A.; Wallis, J. D.; Povey, D. C.; Powell, A. K. J. Chem. Soc., Perkin Trans. 1 1992, 13, 1601.

(9) Piotrowiak, P.; Kobetic, R.; Schatz, T. R.; Tapper, S. Bull. Pol. Acad. Sci. Chem. 1994, 42, 445.

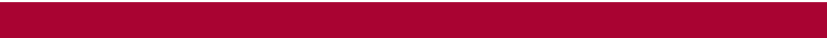

Scheme 1
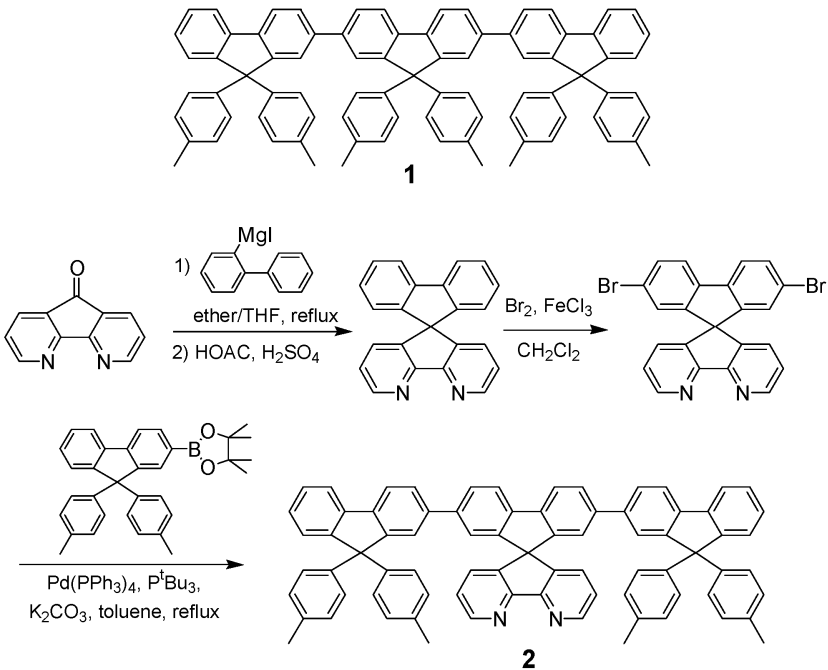

of 4,5-diaza-2', $7^{\prime}$-dibromo-9, $9^{\prime}$-spirobifluorene with the corresponding 9,9-ditolylfluorene pinacol boronic ester in the presence of a catalytic amount of $\mathrm{Pd}\left(\mathrm{PPh}_{3}\right)_{4}$ and cocatalyst $\mathrm{P}^{t} \mathrm{Bu}_{3}$.

Cyclic voltammetry was conducted for probing electrochemical properties (Figure 1). To clearly differentiate

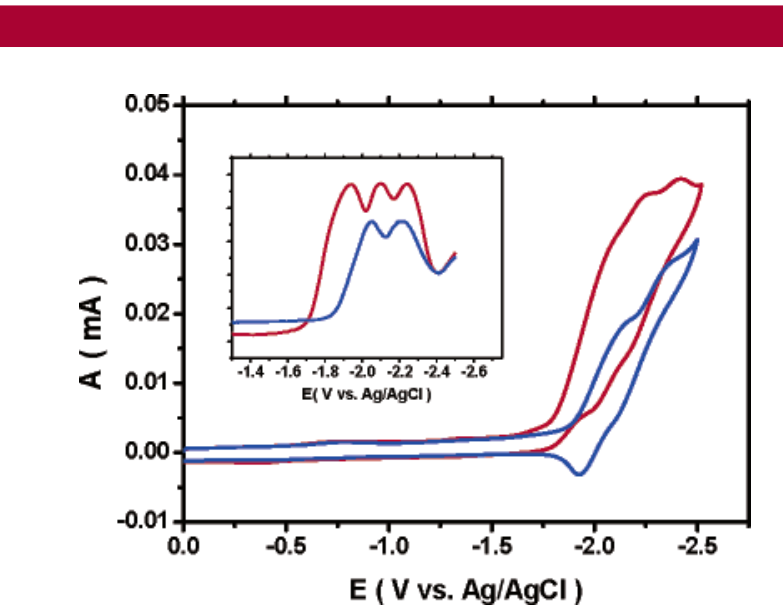

Figure 1. Comparison of reduction cyclic voltammograms of $\mathbf{1}$ (blue) and 2 (red). The inset shows differential pluse voltammetry. For CV experiments, which were performed in THF with $0.1 \mathrm{M}$ of ${ }^{n} \mathrm{Bu}_{4} \mathrm{ClO}_{4}$ as a supporting electrolyte, a glass electrode was used as the working electrode; scan rate $=100 \mathrm{mV} / \mathrm{s}$.

electrochemical behaviors of different compounds, differential pulse voltammetry (DPV) of terfluorenes $\mathbf{1}$ and $\mathbf{2}$ were also conducted under the same conditions (inset of Figure 1). Terfluorene 2 exhibits a reduction onset at -1.76 $\mathrm{V}$, whereas the parent terfluorene $\mathbf{1}$ has a higher reduction onset at $-1.87 \mathrm{~V}$.

Three reduction potentials were detected for $\mathbf{2}$. The origin of these reduction peaks was determined by comparing the reduction potentials of 4,5-diaza-9,9'-spirobifluorene (with 
Table 1. Comparison of Photophyscal Properties of Terfluorenes $\mathbf{1}$ and $\mathbf{2}$

\begin{tabular}{|c|c|c|c|c|c|c|c|}
\hline compd & $\begin{array}{c}\text { abs } \lambda_{\max } \text { solution } \\
(\mathrm{nm})\end{array}$ & $\begin{array}{c}\text { abs } \lambda_{\max } \text { film } \\
(\mathrm{nm})\end{array}$ & $\begin{array}{c}\text { PL } \lambda_{\max } \text { solution } \\
(\mathrm{nm})\end{array}$ & $\begin{array}{c}\text { PL } \lambda_{\max } \text { film } \\
(\mathrm{nm})\end{array}$ & $\begin{array}{l}Q_{\text {sol }} \\
(\%)\end{array}$ & $\begin{array}{c}Q_{\text {film }} \\
(\%)\end{array}$ & $\begin{array}{c}T_{\mathrm{g}} \\
\left({ }^{\circ} \mathrm{C}\right)\end{array}$ \\
\hline 1 & 353 & 353 & $393,413,440$ & $405,428,450$ & 85 & 80 & 190 \\
\hline 2 & 353 & 353 & $393,413,440$ & $405,428,450$ & 78 & 60 & 220 \\
\hline
\end{tabular}

a reversible reduction potential $E_{1 / 2}{ }^{\text {red }}$ at $-2.00 \mathrm{~V}$, Supporting Information) and the parent terfluorene $\mathbf{1}$ (with two quasireversible reduction potentials at -2.07 and $-2.17 \mathrm{~V}$ ). The first reduction peak of $\mathbf{2}$ can be unambiguously ascribed to the reduction occurring on the diazafluorene moiety, while the second and third reduction peaks of $\mathbf{2}$ can be attributed to the reductions occurring on the terfluorene backbone. The assignments are even more obvious in comparing the differential pulse voltammetry of terfluorenes $\mathbf{1}$ and $\mathbf{2}$ (Figure 1 , inset). The slightly higher second and third reduction potentials of $\mathbf{2}$, as compared to those of parent terfluorene 1, could be attributed to Coulombic interaction between the reduced diazafluorene and the terfluorene backbone. On oxidation, terfluorene 2 exhibits reversible oxidation peaks at voltages similar to those of $\mathbf{1}$. Overall, introducing 4,5diazafluorene as the pendant substituent has led to a new terfluorene exhibiting a lower reduction potential compared to that of the parent terfluorene $\mathbf{1}$.
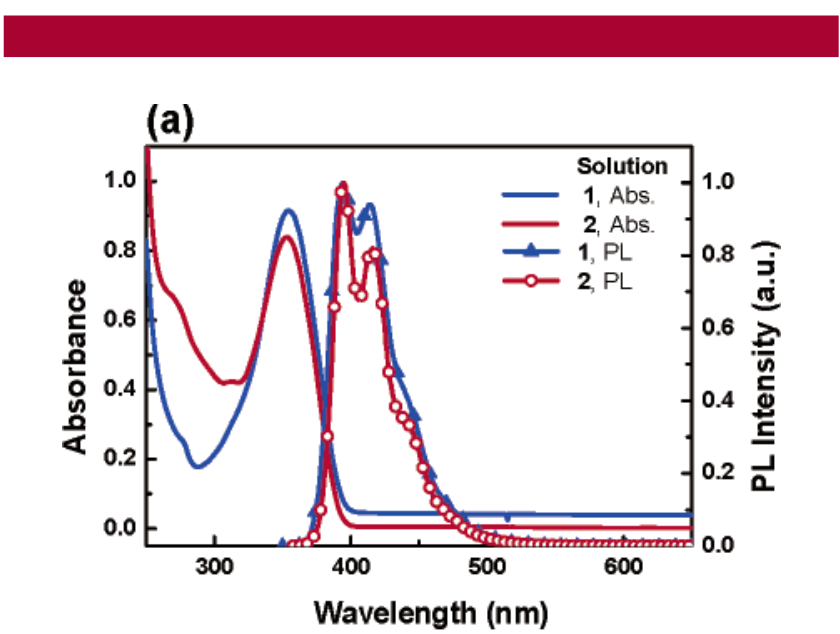

(b)

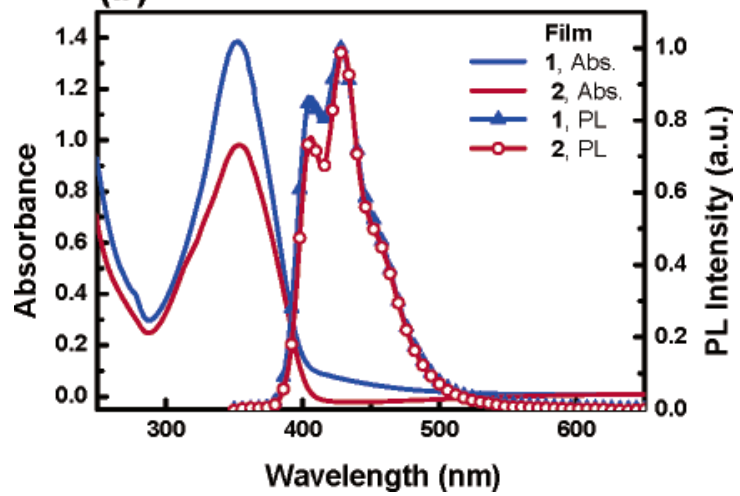

Figure 2. Comparisons of photoluminescence of terfluorene $\mathbf{1}$ and 2 (a) in solution and (b) in solid thin films.
Table 1 and Figure 2 compare the photophysical properties of terfluorenes $\mathbf{1}$ and $\mathbf{2}$. Both terfluorenes exhibit very similar spectroscopic properties: nearly the same lowest-energy absorption bands around $353 \mathrm{~nm}$, similar PL spectra in either solutions (with peaks around 393 and $413 \mathrm{~nm}$ ) or in thin films (with peaks around 405 and $428 \mathrm{~nm}$ ), and similarly high PL quantum yields ( $85 \%$ for $\mathbf{1}$ and $78 \%$ for $\mathbf{2}$ in solutions and slightly lower values for both in thin films). These transitions agree with characteristics of the lowest $\pi-\pi^{*}$ transition of the central terfluorene chromophore and appear to be consistent with the viewpoint that the tetrahedral C9 carbon serves as an effective spacer blocking the substitution from altering the electronic transition on the backbone. On the other hand, bulky and rigid C9 substitutions in both molecules are apparently beneficial to morphological
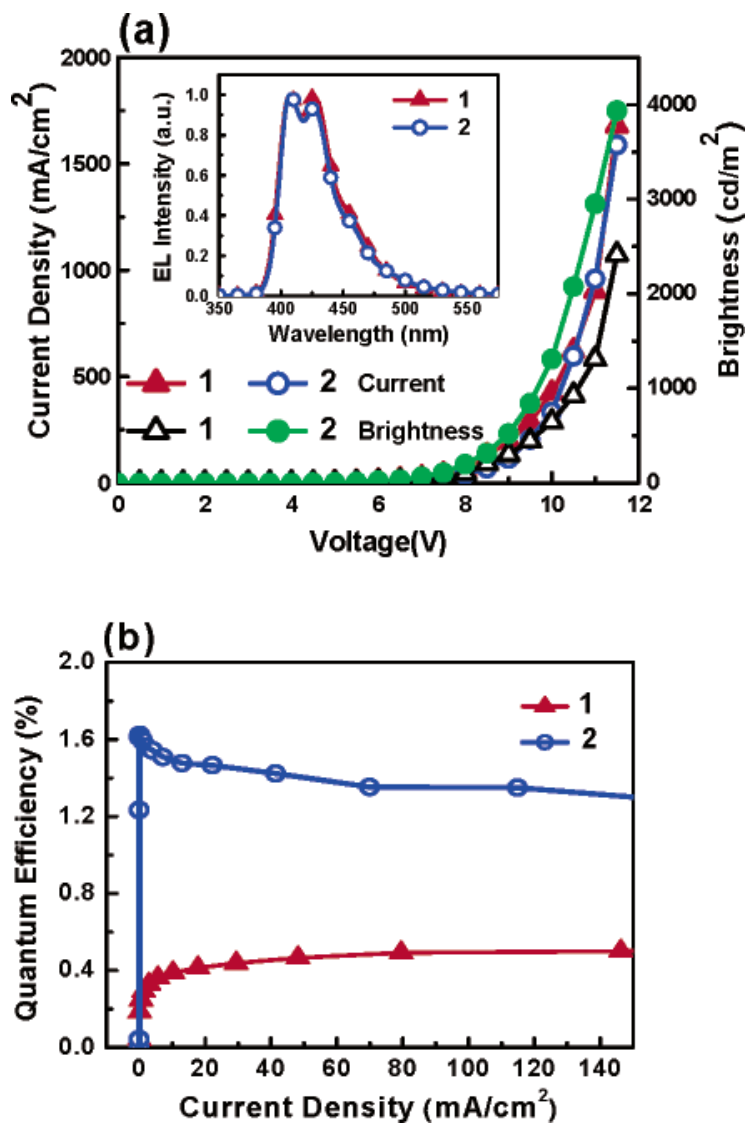

Figure 3. EL characteristics of devices using terfluorenes $\mathbf{1}$ and 2: (a) $\mathrm{L}-\mathrm{V}$ and $\mathrm{I}-\mathrm{V}$ characteristics (Inset: EL spectra of both devices). (b) External EL quantum efficiency vs current. 
stability in thin films, as indicated by the high glass transition temperatures $\left(T_{\mathrm{g}}\right)$ of both compounds (Table 1$)$.

Electroluminescent (EL) devices using these two terfluorenes were compared to investigate the influence of the 4,5diazafluorene substitution on EL properties. The device structure used is ITO anode/PEDT:PSS (300 A)/TCTA (500 $\AA) /$ terfluorene 1 or $2(500 \AA) / \mathrm{LiF}(5 \AA) / \mathrm{Al}$ cathode, where the conducting polymer polyethylene dioxythiophene:polystyrene sulfonate (PEDT:PSS) was used as the hole injection layer, ${ }^{10} 4,4^{\prime}, 4^{\prime \prime}$-tri( $N$-carbazolyl)triphenylamine (TCTA) as the hole-transport layer, ${ }^{10}$ terfluorenes as the emitting/ electron-transport layer, and thin $\mathrm{LiF}$ as the electron-injection layer. ${ }^{10}$ Both devices exhibit pure blue EL similar to PL spectra of terfluorenes (inset of Figure 3a). The device using 2, however, exhibits a lower device voltage (Figure 3a) and a much higher EL external quantum efficiency than the device using 1 (1.6 vs 0.4\% photon/electron, Figure 3b). Performance enhancement with terfluorene 2 indicates that poor performances of the device using $\mathbf{1}$ is due to unbalanced electron injection from the cathode to terfluorene $\mathbf{1}$ and that the new compound terfluorene $\mathbf{2}$ facilitates electron injection and thus largely improves EL performance.

On the basis of the EL, electrochemical, and photophysical results, it is believed that electron injection onto terfluorene 2 in the EL device initially occurs at the spirally linked

(10) (a) Elschner, A.; Bruder, F.; Heuer, H. W.; Jonas, F.; Karbach, A.; Kirchmeyer, S.; Thurm, S.; Wehrmann, R. Synth. Met. 2000, 111, 139. (b) Kuwabara, Y.; Ogawa, H.; Inada, H.; Noma, N.; Shirota, Y. Adv. Mater. 1994, 6, 677. (c) Hung, L. S.; Tang, C. W.; Mason, M. G. Appl. Phys. Lett. 1997, 70, 152. diazafluorene moiety, which due to its lower reduction potential gives enhanced electron injection and device performance. Nevertheless, the final emission originating from the terfluorene backbone indicates that injected electrons undergo efficient electron transfer from the reduced diazafluorene to the terfluorene backbone, where they eventually recombine with injected holes to generate emission characteristic of the terfluorene backbone. Thus, the diazafluorene moiety molecularly spiro-linked to the terfluorene chromophore effectively functions as a bridge for electron injection from cathode to the terfluorene chromophore.

In summary, a novel molecular doping scheme to terfluorenes has been established by incorporating 4,5-diazafluorene as the $\mathrm{C} 9$ substitution of terfluorenes. The original emission characteristics of the terfluorene remains intact, whereas the new terfluorene exhibits a lower reduction onset and enhanced electron injection from the metal cathode. A more efficient OLED device has been achieved by using this novel terfluorene.

Acknowledgment. This work was financially supported by the National Science Council of Taiwan.

Supporting Information Available: Detailed experimental procedure and spectroscopic characterization of new compounds. This material is available free of charge via the Internet at http://pubs.acs.org.

OL0505470 